\title{
Optic disc neovascularisation in diabetic retinopathy: II. Natural history and results of photocoagulation treatment
}

\author{
YUVAL YASSUR, ${ }^{1}$ LINDA W. PICKLE, ${ }^{2}$ STUART L. FINE, \\ LAWRENCE SINGERMAN, DAVID H. ORTH, AND ARNALL PATZ \\ From the Retinal Vascular Service, Wilmer Institute, Johns Hopkins University and Hospital, Baltimore, USA
}

SUMmARY A follow-up study on 67 diabetic patients with new proliferation on the nerve head (neovascularisation of the disc and fibrous proliferation of the disc) was carried out for 4 years. The patients were randomly assigned for treatment with argon laser and xenon photocoagulation in only one eye, with the other eye serving as a control. The disc condition was periodically evaluated for NVD, FPD, and for the relations between them according to a grading taxonomy which was previously established. It was found that there were significant differences in NVD and FPD evolution between treated and untreated eyes. The various parameters concerned with these differences were observed, analysed, and correlated.

Retinal neovascularisation in diabetic retinopathy occurs most commonly on the optic disc. It is the most serious complication of diabetic retinopathy as it frequently leads to vitreous haemorrhage and traction retinal detachment. ${ }^{2}$ The disc has a unique peripapillary capillary plexus. ${ }^{3}$ The absence of an internal limiting membrane over the $\operatorname{disc}^{4}$ may be responsible for the predilection to develop neovascularisation in that area.

Deckert et al..$^{5}$ pointed out the poor prognosis of neovascularisation at the disc (NVD) in juveniles. $50 \%$ of patients who have NVD become legally blind within 2 to 3 years. Beetham et al. ${ }^{6}$ showed that $85 \%$ of untreated patients with proliferative diabetic retinopathy (PDR) and vitreous haemorrhage had this haemorrhage from NVD. Patz and Berkow $^{7-9}$ also pointed out the bad prognosis of eyes with NVD and the fact that $50 \%$ of all patients with disc neovascularisation were legally blind 2 years after the diagnosis of NVD. Davis ${ }^{10}$ traced the fate of NVD, which first increases in size and amount, and then regresses, to be replaced by fibrous proliferation at the disc (FPD), which causes retinal traction. Davis ${ }^{11}$ also stressed the role of posterior vitreous detachment in the pathogenesis of vitreous haemorrhage and retinal detachment in

\footnotetext{
${ }^{1}$ Current address for reprints: Beilinson Hospital and Medical Center, Petach-Tikva, Israel.

${ }^{2}$ From the Department of Biostatistics, Johns Hopkins University and Hospital.
}

NVD and FPD. These studies elicited clearly that disc new proliferation in proliferative diabetic retinopathy (PDR) is a major contributor to diabetic blindness.

Various modes of photocoagulation treatment, such as focal treatment in NVD, panretinal photocoagulation (PRP), and PRP combined with focal treatment in NVD, have been employed during the last 2 decades on eyes with NVD, with various sources of light energy (xenon arc, ruby laser, argon laser, and krypton laser). Various studies on results of treatment reported various conclusions. Aiello et $a .^{12}{ }^{13}$ and Beetham et al. ${ }^{6}$ reported favourable results of NVD regression in patients treated with ruby laser PRP, particularly when the treatment was performed early. Wessing and MeyerSchwickerath $^{14}$ reported only $20 \%$ regression of NVD in patients treated with xenon retinal photocoagulation, while Krill et al. ${ }^{15}$ reported much better results with the same modality, if treatment were extensive. Okun ${ }^{16}{ }^{17}$ and Taylor and Dobree ${ }^{1}$ also reported considerable NVD regression after extensive xenon PRP. Other reports claimed beneficial effects of argon laser photocoagulation in eliminating NVD, either by PRP alone ${ }^{18-20}$ or by PRP and additional focal treatment, if necessary, at various times after PRP has been completed. ${ }^{2} \mathbf{~}^{21-23}$ L'Esperance ${ }^{24} 25$ stressed the good results of focal treatment on NVD. Arribas et al. ${ }^{26}$ claimed to try all photocoagulation sources and techniques, and concluded that xenon arc PRP was most effective 
if applied early. They stated that good results cannot be obtained by xenon arc or argon laser when NVD was extensive and highly elevated into the vitreous.

Pat $\mathrm{z}^{9}$ called for reports from controlled studies. These were first obtained from the British Multicentric Photocoagulation Trial, ${ }^{27}$ which reported much regression of NVD in xenon-treated eyes; from the Diabetic Retinopathy Study Research Group, ${ }^{28}{ }^{29}$ which showed that eyes with NVD that were treated either with xenon arc or argon laser, especially early in the disease, had a considerable reduction of NVD; and from Hercules et al., ${ }^{30}$ who showed that in eyes treated by argon PRP alone there was a much higher reduction of NVD during the 3 years of follow-up than in untreated eyes with NVD, particularly if treated early in the disease.

In a previous study ${ }^{31}$ a taxonomy based on detailed parameters of disc new proliferation was laid out so that NVD and FPD could be evaluated separately. The present study involves a 4-year follow-up of treated and untreated eyes with disc new proliferation that examines the fate of this proliferation and the relation between NVD and FPD.

\section{Material and methods}

During 1973-4, before any results of controlled randomised therapeutic studies for NVD were available, patients seen in our clinic were randomly assigned for photocoagulation treatment. These patients had NVD of various grades, according to a grading system described by Yassur et al., ${ }^{31}$ and only one eye was randomly assigned for treatment. None of the patients had pituitary ablation or previous photocoagulation treatment. Initially we reviewed the records of 83 consecutive patients assigned for a 4-year follow-up, but 16 patients dropped out at various stages because of death, inadequate follow-up, or because the 'control' eye was also treated. Therefore 67 patients, 35 of whom were men and 32 women, aged 16-72 years, with diabetes duration of 1-40 years (mean 18.4 years) were followed up for 4 years. Forty-five patients had argon laser photocoagulation treatment, and 22 patients had xenon arc photocoagulation treatment. The treatment consisted of PRP, according to the treatment protocol of the Manual of Operation of the Diabetic Retinopathy Study. ${ }^{32}$ All the eyes had adequate treatment from the point of view of the pattern and number, size, and intensity of the photocoagulation burns. Only 2 of the argon lasertreated patients had additional focal treatment to NVD within 6 months after completing the PRP.

The disc new proliferation, NVD and FPD, of the treated and untreated eyes was evaluated and graded at the beginning of the study and then periodically every 6 weeks to 1 year up to 4 years. The evaluation of NVD and FPD was done according to the 6 parameters described in the grading system:31 number of involved disc quadrants, calibre of new vessels, density of NVD or FPD, total area of NVD or FPD proliferation, plane of NVD or FPD proliferation, and fluorescein leakage from NVD. The overall grading for each disc was assessed on the follow-up examinations by using stereophotographs and fluorescein angiography.

\section{Results}

There were marked and significant differences in most of the recorded parameters for NVD and FPD in treated and untreated eyes.

Fig. 1 demonstrates the deep gap between treated and untreated eyes concerning the number of quadrants involved in NVD.

Fig. 2 demonstrates some gap between treated and untreated eyes concerning calibre of vessels in NVD frond; however, all 3 curves have a mild upward inclination, which can be attributed to the 'maturing' process of blood vessels which remained in fronds.

Fig. 3 demonstrates the gap in density in NVD

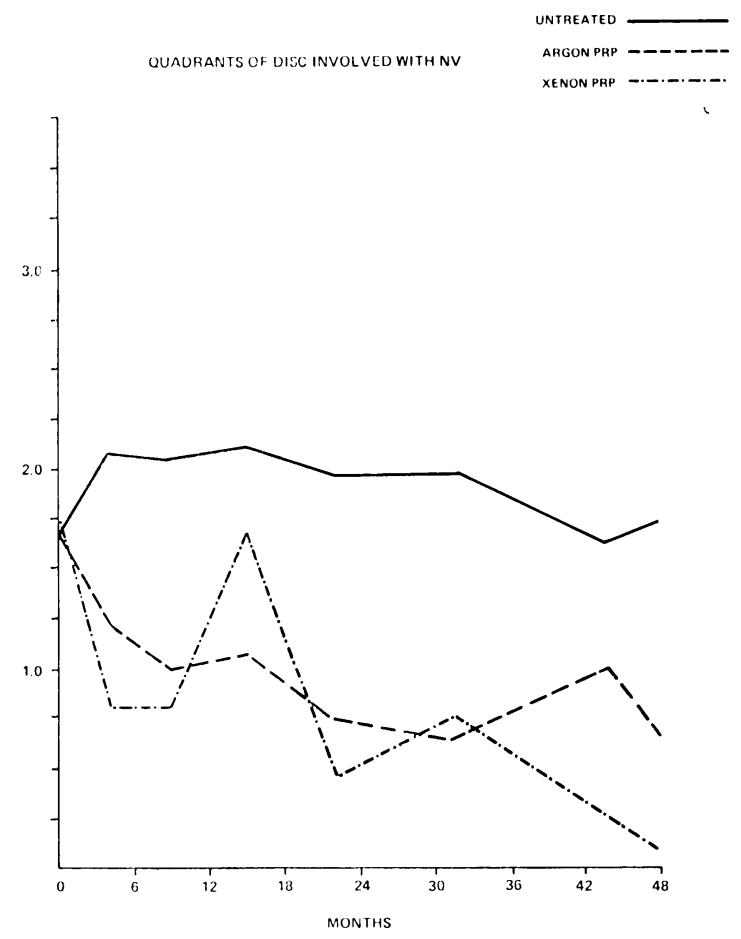

Fig. 1 Number of quadrants involved with NVD. 


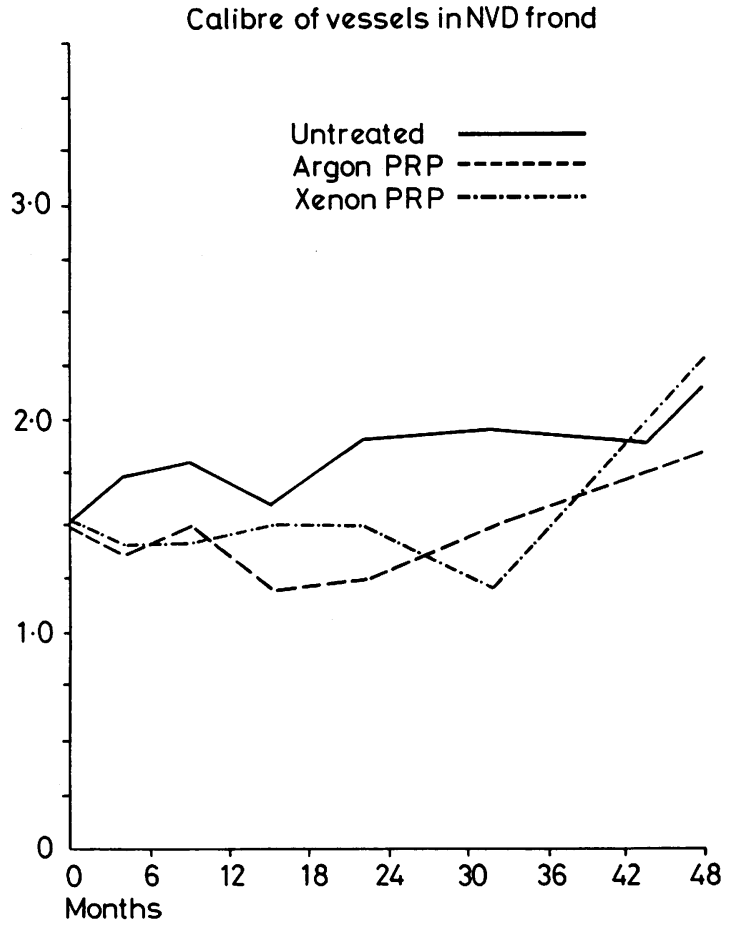

Fig. 2 Calibre of vessels in NVD frond.

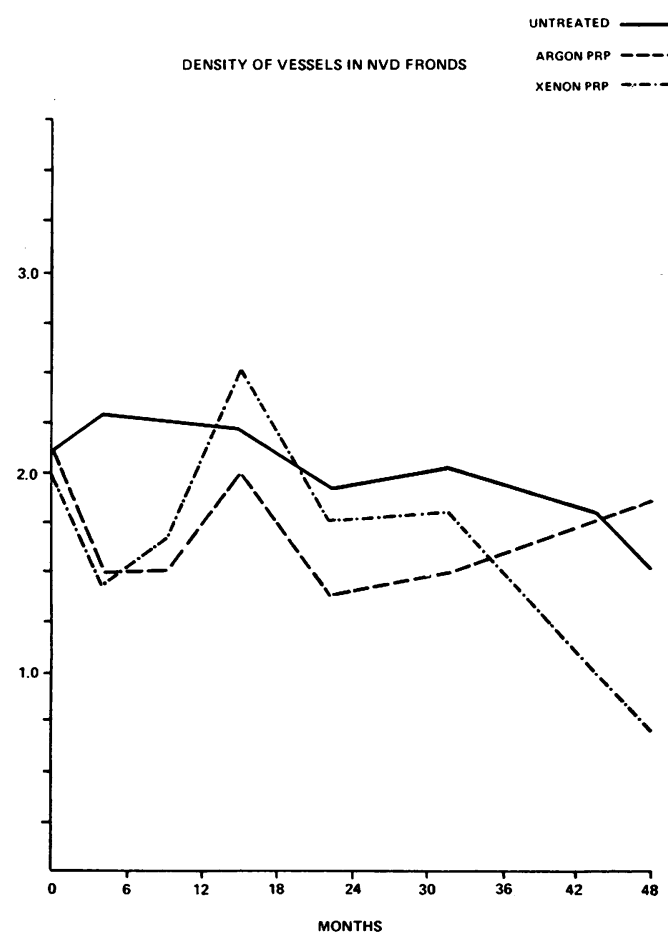

Fig. 3 Density of vessels in NVD frond. fronds. The initial deep gap between the treated and untreated eyes is due to the good response to treatment, with partial regression of vessels in existing fronds.

Fig. 4 demonstrates the gap induced by treatment in total area of proliferation of NVD between treated and untreated eyes. This gap is due to reduction in NVD in treated eyes. The 'ups and downs' in the curves can be attributed to the dynamic transformation of existing NVD to FPD during various phases of the long follow-up period.

Fig. 5 demonstrates the plane of proliferation of

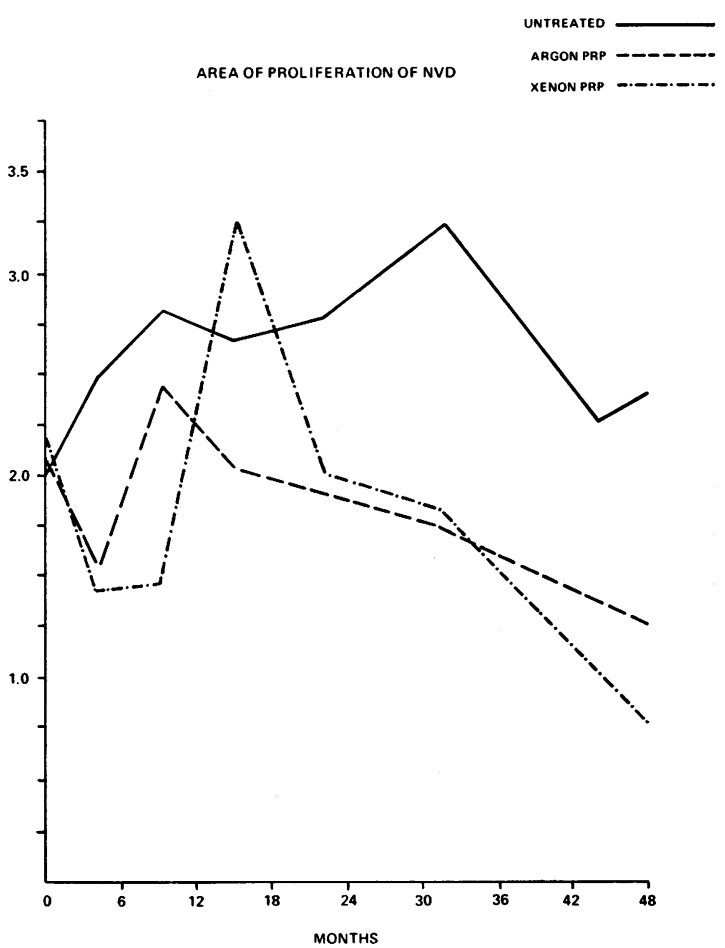

Fig. 4 Total area of proliferation of NVD, measured in $D D$.

NVD in treated and untreated group. It is true that the vitreous continued to detach further from the retina in the untreated eyes, as a signal of increased disc new proliferation, as demonstrated earlier by Davis. ${ }^{11}$ However, xenon arc treated eyes also showed such a rising slope, which may be explained by more heating of the vitreous with xenon therapy compared to argon therapy.

Tables 1-7 demonstrate additional aspects of the follow-up investigation. The numbers in italics represent those eyes in which no change of grade occurred. The numbers to the left of them represent eyes with a decrease in grade, or less involvement. 
The numbers to the right of them represent eyes with an increased grade, or more involvement.

Table 1, which represents NVD grade of argontreated eyes, demonstrates that most of the eyes (71\%) had decrease of NVD grade following treatment, and about one-fifth $(18 \%)$ remained at the same NVD grade at the 4-year follow-up.

Table 2, which represents NVD grade of xenontreated eyes, demonstrates that here too about

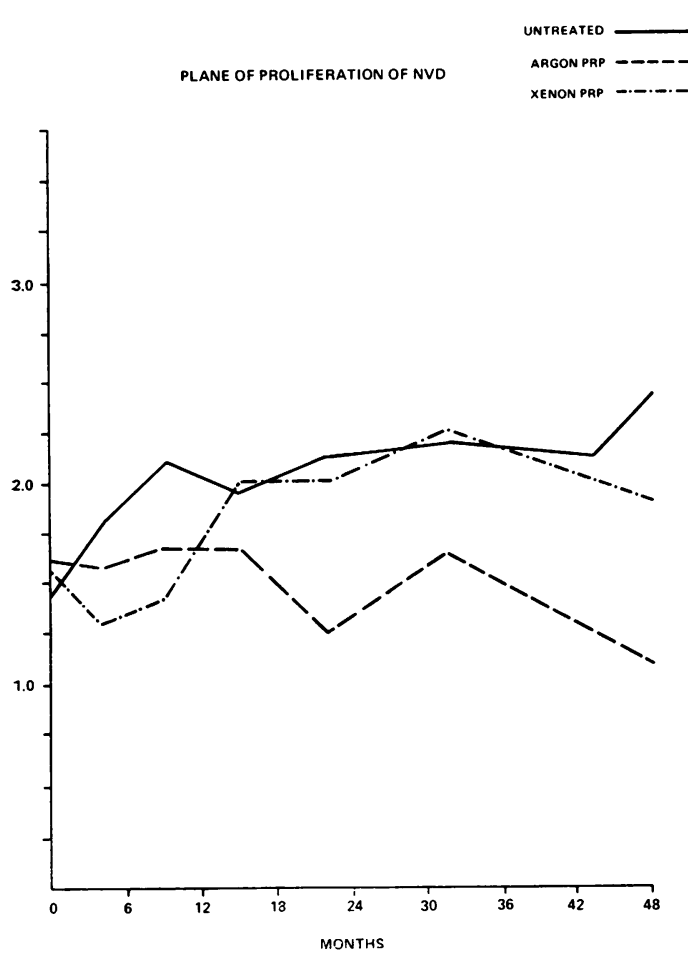

Fig. 5 Plane of proliferation of NVD.

Table 1 Grade of NVD before treatment versus grade 4 years after argon laser treatment

\begin{tabular}{lrrrrrr}
\hline \multicolumn{7}{c}{ Last visit } \\
\hline Grade & 0 & 1 & 2 & 3 & 4 & $\begin{array}{c}\text { Total } \\
\text { number } \\
\text { of eyes }\end{array}$ \\
\hline 0 & 0 & 1 & 0 & 0 & 0 & 1 \\
1 & 11 & 5 & 4 & 0 & 0 & 20 \\
2 & 6 & 4 & 2 & 0 & 0 & 12 \\
3 & 4 & 2 & 4 & 1 & 0 & 11 \\
4 & 0 & 1 & 0 & 0 & 0 & 1 \\
\hline \multirow{2}{*}{$\begin{array}{c}\text { Total number } \\
\text { of eyes }\end{array}$} & 21 & 13 & 10 & 1 & 0 & 45 \\
\hline
\end{tabular}

Table 2 Grade of NVD before treatment versus grade 4 years after xenon arc treatment

\begin{tabular}{|c|c|c|c|c|c|c|c|}
\hline & \multicolumn{7}{|c|}{ Last visit } \\
\hline & Grade & 0 & 1 & 2 & 3 & 4 & $\begin{array}{l}\text { Total } \\
\text { number } \\
\text { of eyes }\end{array}$ \\
\hline \multirow{6}{*}{ 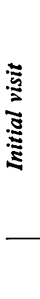 } & 0 & 0 & 0 & 0 & 0 & 0 & 0 \\
\hline & 1 & 5 & 2 & 2 & 1 & 0 & 10 \\
\hline & 2 & 4 & 2 & 1 & 0 & 0 & 7 \\
\hline & 3 & 3 & 0 & 0 & 1 & 0 & 4 \\
\hline & 4 & 0 & 0 & 0 & 0 & 1 & 1 \\
\hline & $\begin{array}{l}\text { Total number } \\
\text { of eyes }\end{array}$ & 12 & 4 & 3 & 2 & 1 & 22 \\
\hline
\end{tabular}

Table 3 Grade of NVD at first visit versus grade 4 years later in untreated eyes

\begin{tabular}{lrrrrrc}
\hline \multicolumn{7}{c}{ Last visit } \\
\hline Grade & 0 & 1 & 2 & 3 & 4 & $\begin{array}{c}\text { Total } \\
\text { number } \\
\text { of eyes }\end{array}$ \\
\hline 0 & 0 & 2 & 0 & 0 & 0 & 2 \\
1 & 4 & 11 & 16 & 13 & 1 & 45 \\
2 & 1 & 4 & 1 & 2 & 1 & 9 \\
3 & 0 & 3 & 2 & 4 & 1 & 10 \\
4 & 0 & 1 & 0 & 0 & 0 & 1 \\
\hline \multirow{3}{*}{$\begin{array}{c}\text { Total number } \\
\text { of eyes }\end{array}$} & 5 & 21 & 19 & 19 & 3 & 67 \\
\hline
\end{tabular}

two-thirds of the eyes $(64 \%)$ had a decrease of NVD grade following treatment, and one-fourth of the eyes $(23 \%)$ remained at the same NVD grade.

The 2 treated groups, when combined, had $69 \%$ of eyes with decreased NVD grade, 19\% of eyes with unchanged NVD grade, and only $12 \%$ with increased NVD grade.

Table 3, which represents NVD grade for untreated eyes, demonstrates that the results concerning NVD were much worse than in the treated eyes. Decrease in NVD grade occurred in only $22 \%$, unchanged grade occurred in $24 \%$, and increase in NVD grade occurred in $54 \%$ of eyes.

Fig. 6, which graphically represents the change in NVD overall grade during the 4-year follow-up, demonstrates the deep gap created between untreated and treated eyes as a result of the treatment. The advantage of treatment in reducing NVD involvement is significant. The decline in curves is explained partly by disappearance of NVD and partly by replacement of new vessels by fibrous 


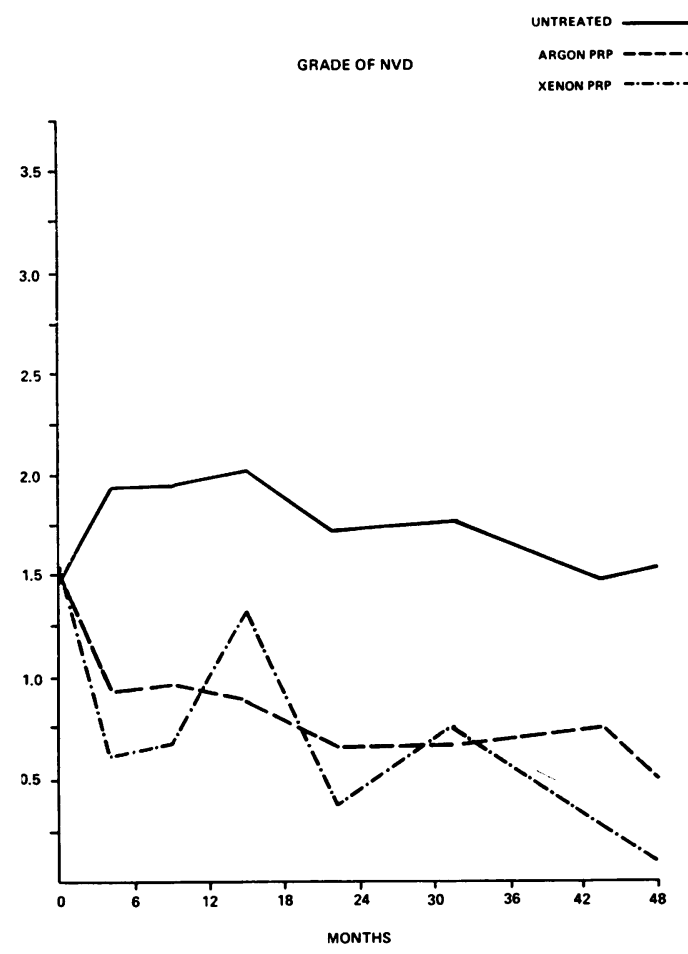

Fig. 6 Overall grade of NVD.

proliferation; however, this disappearance and replacement in the treated eyes occurs at a much lower level of grading.

Table 4, which summarises the fate of NVD during the follow-up period, demonstrates the significant difference between treated eyes, of which $88 \%$ either decreased or remained at the same NVD grade, and untreated eyes, of which only $46 \%$ either decreased or remained at the same NVD grade.

Table 5 shows the percentage of eyes which had no NVD at the end of the follow-up period from those who had NVD at the beginning of the study in each NVD grade group. It is demonstrated that, in the argon- and xenon-treated eyes, between $50 \%$ and $75 \%$ of eyes in NVD grade 1-3 groups eventually had no NVD, while in the untreated eyes only $6-14 \%$ eventually had no NVD. The number of eyes in this study in group 4 NVD grade was too small to draw conclusions; however, the bad prognosis of such eyes has already been established.

Table 6 demonstrates the high significance of difference concerning the increase in NVD grade between treated and untreated eyes. There is no difference in the increase of NVD grade between argon- and xenon-treated eyes: both did equally well compared to untreated eyes, which showed a significant increase in NVD overall grade.
Table 7 demonstrates that the decrease in NVD grade in both argon- and xenon-treated eyes was significantly higher than in the untreated eyes. Here too there is no significant difference between argonand xenon-treated eyes: in both treated groups the NVD grade decreased considerably.

Table 8, which represents the FPD grade in argon-treated eyes, demonstrates that FPD grade increased in $31 \%$, remained the same in $60 \%$, and decreased in $9 \%$. This reflects the fact that in a good majority of the treated patients in which regression of NVD occurred the regression happened with the NVD not being replaced by FPD.

Table 4 The fate of NVD during the 4 years of follow-up-summary table (numbers of patients in parentheses)

\begin{tabular}{lccll}
\hline $\begin{array}{l}\text { NVD } \\
\text { grade }\end{array}$ & $\begin{array}{l}\text { Argon } \\
\text { treated } \\
\text { eyes }\end{array}$ & $\begin{array}{l}\text { Xenon } \\
\text { treated } \\
\text { eyes }\end{array}$ & $\begin{array}{l}\text { All } \\
\text { treated } \\
\text { eyes }\end{array}$ & $\begin{array}{l}\text { Untreated } \\
\text { eyes }\end{array}$ \\
\hline Decrease & $\begin{array}{c}71 \% \\
(32)\end{array}$ & $\begin{array}{l}64 \% \\
(14)\end{array}$ & $\begin{array}{l}69 \% \\
(46)\end{array}$ & $\begin{array}{l}22 \% \\
(15)\end{array}$ \\
Same & $18 \%$ & $23 \%$ & $19 \%$ & $24 \%$ \\
Increase & $11 \%$ & $(5)$ & $(13)$ & $(16)$ \\
& $(5)$ & $(3)$ & $12 \%$ & $54 \%$ \\
Total & $100 \%$ & $100 \%$ & $100 \%$ & $100 \%$ \\
& $(45)$ & $(22)$ & $(67)$ & $(67)$ \\
\hline
\end{tabular}

Table 5 Percentage of eyes graded 0 for NVD on last visit by initial grade

\begin{tabular}{lllll}
\hline & \multicolumn{4}{l}{ Initial grade } \\
\cline { 2 - 5 } & 1 & 2 & 3 & 4 \\
\hline Argon treated & $72 \%$ & $45 \%$ & $36 \%$ & $0 \%$ \\
Xenon treated & $55 \%$ & $57 \%$ & $75 \%$ & $0 \%$ \\
Untreated eye & $14 \%$ & $6 \%$ & $0 \%$ & $0 \%$ \\
\hline
\end{tabular}

Table 6 Significance of increase in NVD grade during the 4-year follow-up period

\begin{tabular}{|c|c|c|c|}
\hline Group & $\begin{array}{l}\% \text { of Eyes } \\
\text { with increased } \\
\text { NVD grade }\end{array}$ & $Z$ & $P$ value \\
\hline $\begin{array}{l}\text { Argon treated eyes } \\
\text { Untreated eyes }\end{array}$ & $\begin{array}{l}11 \% \\
54 \%\end{array}$ & $4 \cdot 08$ & $<0.001$ \\
\hline $\begin{array}{l}\text { Xenon treated eyes } \\
\text { Untreated eyes }\end{array}$ & $\begin{array}{l}13 \% \\
54 \%\end{array}$ & $2 \cdot 90$ & 0.004 \\
\hline $\begin{array}{l}\text { All treated eyes } \\
\text { Untreated eyes }\end{array}$ & $\begin{array}{l}12 \% \\
54 \%\end{array}$ & $4 \cdot 51$ & $<0.001$ \\
\hline $\begin{array}{l}\text { Argon treated eyes } \\
\text { Xenon treated eyes }\end{array}$ & $\begin{array}{l}11 \% \\
13 \%\end{array}$ & -0.30 & 0.76 \\
\hline
\end{tabular}


Table 7 Significance of decrease in NVD grade during the 4-year follow-up period

\begin{tabular}{|c|c|c|c|}
\hline Group & $\begin{array}{l}\% \text { of Eyes } \\
\text { with decreased } \\
\text { NVD grade }\end{array}$ & $Z$ & $P$ value \\
\hline $\begin{array}{l}\text { Argon treated eyes } \\
\text { Untreated eyes }\end{array}$ & $\begin{array}{l}71 \% \\
29 \%\end{array}$ & $-4 \cdot 64$ & $<0.001$ \\
\hline $\begin{array}{l}\text { Xenon treated eyes } \\
\text { Untreated eyes }\end{array}$ & $\begin{array}{l}64 \% \\
29 \%\end{array}$ & $-2 \cdot 93$ & $<0.004$ \\
\hline $\begin{array}{l}\text { All treated eyes } \\
\text { Untreated eyes }\end{array}$ & $\begin{array}{l}69 \% \\
22 \%\end{array}$ & -4.95 & $<0.001$ \\
\hline $\begin{array}{l}\text { Argon treated eyes } \\
\text { Xenon treated eyes }\end{array}$ & $\begin{array}{l}71 \% \\
64 \%\end{array}$ & 0.62 & 0.52 \\
\hline
\end{tabular}

Table 8 Grade of FPD before treatment versus grade 4 years after argon laser treatment

\begin{tabular}{|c|c|c|c|c|c|c|c|}
\hline \multicolumn{8}{|c|}{ Last visit } \\
\hline & Grade & 0 & 1 & 2 & 3 & 4 & $\begin{array}{l}\text { Total } \\
\text { number } \\
\text { of eyes }\end{array}$ \\
\hline \multirow{6}{*}{ 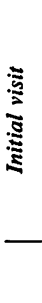 } & 0 & 22 & 5 & 3 & 1 & 0 & 31 \\
\hline & 1 & 2 & 5 & 2 & 1 & 1 & 11 \\
\hline & 2 & 0 & 1 & 0 & 1 & 0 & 2 \\
\hline & 3 & 0 & 0 & 1 & 0 & 0 & 1 \\
\hline & 4 & 0 & 0 & 0 & 0 & 0 & 0 \\
\hline & $\begin{array}{l}\text { Total number } \\
\text { of eyes }\end{array}$ & 24 & 11 & 6 & 3 & 1 & 45 \\
\hline
\end{tabular}

Table 9 Grade of FPD before treatment versus grade 4 years after xenon treatment

\begin{tabular}{lllllll}
\hline Grade & 0 & 1 & 2 & 3 & 4 & $\begin{array}{l}\text { Total } \\
\text { number } \\
\text { of eyes }\end{array}$ \\
\hline 0 & 6 & 5 & 2 & 2 & 2 & 17 \\
1 & 0 & 0 & 3 & 0 & 0 & 3 \\
2 & 0 & 0 & 0 & 0 & 2 & 2 \\
3 & 0 & 0 & 0 & 0 & 0 & 0 \\
4 & 0 & 0 & 0 & 0 & 0 & 0 \\
\hline $\begin{array}{l}\text { Total number } \\
\text { of eyes }\end{array}$ & 6 & 5 & 5 & 2 & 4 & 22 \\
\hline
\end{tabular}

Table 9, which represents FPD grade in xenontreated patients, demonstrates that more than twothirds of the eyes $(73 \%)$ showed increase in FPD grade, and less than one-third $(27 \%)$ showed the same grade of FPD. None of the eyes had a decrease in FPD grade. This happened because in a good majority of eyes in this group the NVD which regressed was replaced by FPD, and only in onethird the NVD which regressed was not replaced by fibrous tissue.

Table 10, which represents the FPD grade in untreated eyes, demonstrates that in more than half of the eyes $(57 \%)$ there was a considerable increase in FPD grade, while in less than half of the eyes $(43 \%)$ the FPD grade remained the same. This reflects the fact that as NVD continued to grow and was later replaced by FPD, the amount of fibrosis on the disc increased too.

Fig. 7, which represents the plane of proliferation

Table 10 Grade of FPD at first visit versus grade 4 years later in untreated eyes

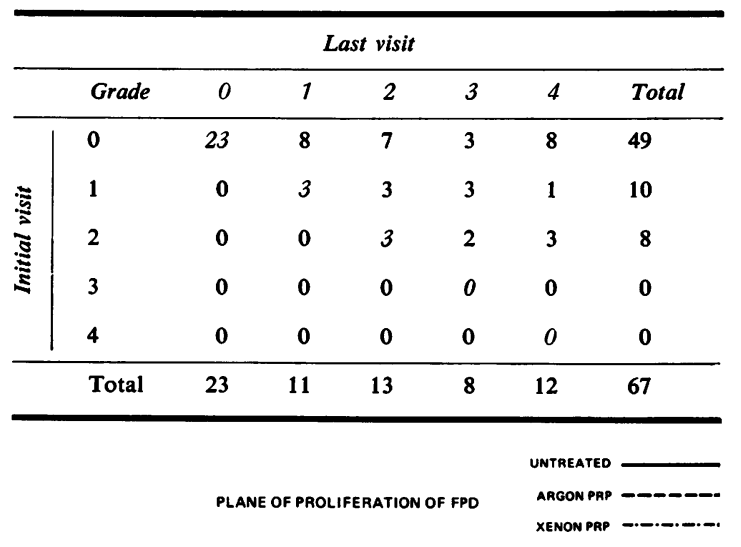

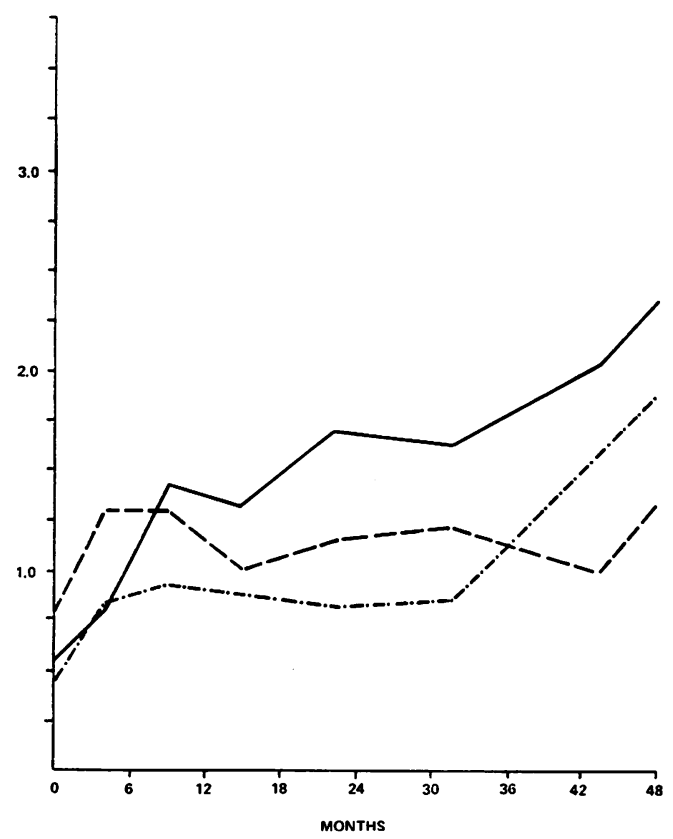

Fig. 7 Plane of proliferation of FPD. 
of FPD, demonstrates that there is a gap between the curves of treated and untreated eyes, although all 3 curves show an upward inclination, which is due to the continuous detachment of the posterior vitreous face away from the surface of the retina. Again, as in the plane of proliferation for NVD, the rate of this detachment is more accelerated in untreated eyes, and somehow more accelerated eventually in xenon-treated than in argon-treated eyes, perhaps due to more contraction of vitreous in xenon-treated eyes.

Fig. 8, which represents the overall grade of FPD, demonstrates the deep gap between treated and untreated eyes. This is attributed to the fact that, as more NVD grows, it is later replaced by more FPD; and the earlier the growth of NVD is prevented the less likely that FPD will emanate from the disc later. The curve of argon-treated eyes suggests that, immediately after the first response to PRP treatment, some of the regressing NVD is replaced by FPD, but later there is some regression of some of the fibrotic tissue and also dynamic transformation of NVD to FPD on a much lower level than for untreated eyes. In the xenon-treated eyes the process was similar to that in the argon-treated eyes, except that the net effect was greater develop-

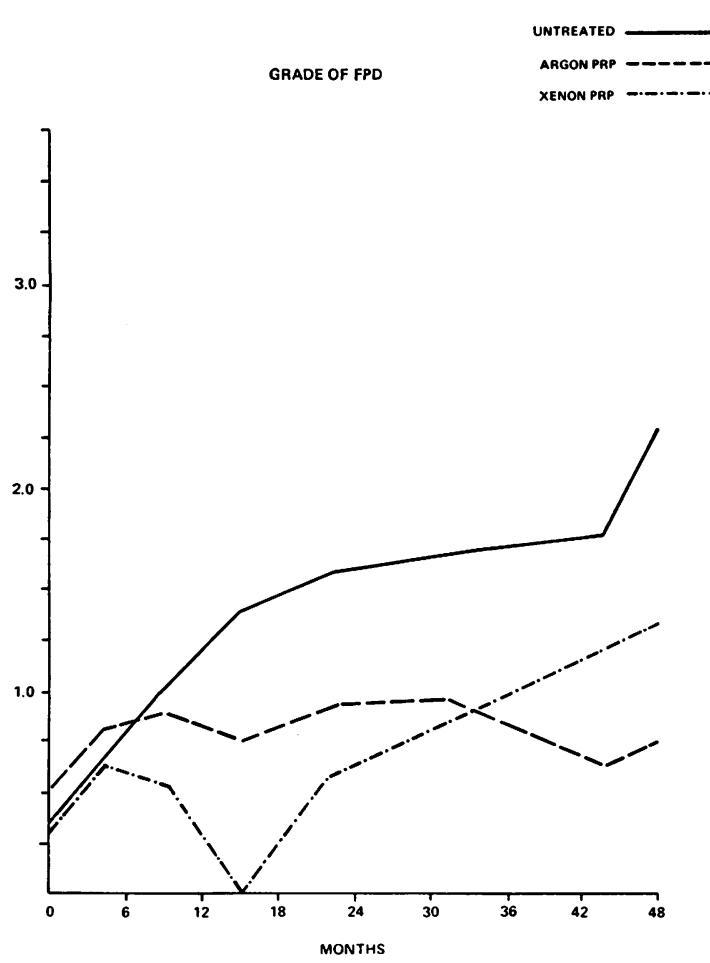

Fig. 8 Overall grade of FPD.
Table 11 The fate of FPD during the 4 years of follow-up-summary table (number of paitents in parentheses)

\begin{tabular}{|c|c|c|c|c|}
\hline FPD grade & $\begin{array}{l}\text { Argon } \\
\text { treated } \\
\text { eyes }\end{array}$ & $\begin{array}{l}\text { Xenon } \\
\text { treated } \\
\text { eyes }\end{array}$ & $\begin{array}{l}\text { All } \\
\text { treated } \\
\text { eyes }\end{array}$ & $\begin{array}{c}\text { Untreated } \\
\text { eyes }\end{array}$ \\
\hline Decrease & $\begin{array}{l}9 \% \\
(4)\end{array}$ & $\begin{array}{l}0 \% \\
(0)\end{array}$ & $\begin{array}{l}9 \% \\
(6)\end{array}$ & $\begin{array}{l}0 \% \\
(0)\end{array}$ \\
\hline Same & $\begin{array}{l}60 \% \\
(27)\end{array}$ & $\begin{array}{c}27 \% \\
(6)\end{array}$ & $\begin{array}{l}40 \% \\
(32)\end{array}$ & $\begin{array}{l}43 \% \\
(29)\end{array}$ \\
\hline Increase & $\begin{array}{l}31 \% \\
(14)\end{array}$ & $\begin{array}{l}73 \% \\
(16)\end{array}$ & $\begin{array}{l}42 \% \\
(29)\end{array}$ & $\begin{array}{l}57 \% \\
(38)\end{array}$ \\
\hline Total & $\begin{array}{c}100 \% \\
(45)\end{array}$ & $\begin{array}{c}100 \% \\
(22)\end{array}$ & $\begin{array}{c}100 \% \\
(67)\end{array}$ & $\begin{array}{c}100 \% \\
(67)\end{array}$ \\
\hline
\end{tabular}

Table 12 Percentage of eyes graded 0 for FPD on last visit by initial grade

\begin{tabular}{|c|c|c|c|c|c|}
\hline Initial grade & 0 & 1 & 2 & 3 & 4 \\
\hline Argon treated & $71 \%$ & $18 \%$ & $0 \%$ & $0 \%$ & $0 \%$ \\
\hline Xenon treated & $46 \%$ & $0 \%$ & $0 \%$ & $0 \%$ & $0 \%$ \\
\hline Untreated eyes & $26 \%$ & $0 \%$ & $0 \%$ & $0 \%$ & $0 \%$ \\
\hline
\end{tabular}

ment of FPD compared to the argon-treated eyes.

Table 11 summarises the fate of FPD in the treated and untreated eyes. It is demonstrated that about half of both treated and untreated eyes had an increase of FPD grade, about half had the same FPD grade, and only one-tenth of treated eyes had a decrease in FPD grade. This demonstrates again that the basic process of NVD disappearance is either a mere regression or regression and replacement by FPD; the less NVD which exists and the earlier NVD disappears, the less FPD occurs later. Most of the FPD in treated eyes occurred on a lower grade level than in untreated eyes.

Table 12 represents the percentage of eyes which had no FPD at the end of the follow-up period from those who had no FPD at the beginning of the study in each FPD grade group. In the argon-treated eyes as high as $71 \%$ which were graded 0 for FPD remained 0 , and $18 \%$ of eyes graded 1 for FPD remained 1. All the rest had some FPD to some degree. In xenon-treated eyes $46 \%$ previously graded as 0 still remained 0 for FPD, while all the others had some FPD grading. In the untreated group only $26 \%$ of eyes which had 0 FPD grade remained so, while the rest developed FPD. This again demonstrates the fact that evolution of NVD to FPD calls for eliminating NVD sooner in order to prevent FPD complications.

Table 13, which represents the significance of increase in FPD grade, demonstrates that in our 
Table 13 Significance of increase in FPD grade during the 4-year follow-up period

\begin{tabular}{llll}
\hline Group & $\begin{array}{l}\text { \% of Eyes } \\
\text { with increased } \\
F P D \text { grade }\end{array}$ & $Z$ & $P$ value \\
\hline $\begin{array}{lll}\text { Argon treated eyes } \\
\text { Untreated eyes }\end{array}$ & $\begin{array}{l}31 \% \\
57 \%\end{array}$ & 2.81 & 0.005 \\
$\begin{array}{l}\text { Xenon treated eyes } \\
\text { Untreated eyes }\end{array}$ & $73 \%$ & -1.19 & 0.23 \\
$\begin{array}{l}\text { All treated eyes } \\
\text { Untreated eyes }\end{array}$ & $57 \%$ & & \\
$\begin{array}{l}\text { Argon treated eyes } \\
\text { Xenon treated eyes }\end{array}$ & $37 \%$ & 1.81 & 0.7 \\
\hline
\end{tabular}

Table 14 Significance of decrease of FPD grade during the 4-year follow-up period

\begin{tabular}{|c|c|c|c|}
\hline Group & $\begin{array}{l}\% \text { of Eyes } \\
\text { with decreased } \\
\text { FPD grade }\end{array}$ & $Z$ & $P$ value \\
\hline $\begin{array}{l}\text { Argon treated eyes } \\
\text { Untreated eyes }\end{array}$ & $\begin{array}{l}9 \% \\
0 \%\end{array}$ & -3.01 & 0.002 \\
\hline $\begin{array}{l}\text { Xenon treated eyes } \\
\text { Untreated eyes }\end{array}$ & $\begin{array}{l}0 \% \\
0 \%\end{array}$ & 0 & 0 \\
\hline $\begin{array}{l}\text { All treated eyes } \\
\text { Untreated eyes }\end{array}$ & $\begin{array}{l}7 \% \\
0 \%\end{array}$ & -2.56 & 0.01 \\
\hline $\begin{array}{l}\text { Argon treated eyes } \\
\text { Xenon treated eyes }\end{array}$ & $\begin{array}{l}9 \% \\
0 \%\end{array}$ & 1.37 & 0.7 \\
\hline
\end{tabular}

data the differences were significant concerning only argon-treated eyes versus untreated eyes, and argontreated eyes versus xenon-treated eyes. However, it was our clinical impression that the difference was true also for xenon-treated eyes, and that FPD grade increased more in untreated eyes than in these eyes too.

Table 14, which represents the significance of decrease of FPD grade, demonstrates clearly that the difference in reduction of FPD grade, if occurring, between all treated eyes and untreated eyes was very significant. It was also our clinical observation that only eyes which were treated early enough and in which the FPD grade was mild showed the capability for this mild fibrotic tissue to disappear completely or considerably.

Fig. 9 demonstrates graphically the process of disappearance of NVD and its replacement by FPD. In all 3 curves there is a decline which is attributed to that mutual relationship between NVD and FPD. The less time NVD exists and the less NVD to exist, the sharper is the initial decline; and later the gap between treated and untreated eyes is generally maintained, with some variations during the follow-up period. The downward inclination of the curves indicates that when the NVD grade decreases the FPD grade increases.

Fig. 10 demonstrates the changes in visual acuity in treated and untreated eyes. There is a permanent increase of the curve of untreated eyes, representing the fact that the visual acuity in the untreated eyes steadily decreased during the 4-year follow-up period. The curve of argon-treated eyes did not change much. The curve of the xenon-treated eyes showed very wide variations during the follow-up period.

\section{Discussion}

The taxonomy for grading system which was used in this study enabled us to provide a careful evaluation of the disc status in any of the 4-year follow-up visits, and to consider separately vascular and fibrous proliferation at the disc and to correlate them with each other.

It was shown that the evolution of NVD and FPD in treated eyes was significantly different from that in untreated eyes. All the parameters involved in overall grading of NVD and FPD were influenced by the argon and xenon treatment in such a way that disc proliferation was reduced.

The treatment seems to change the natural history
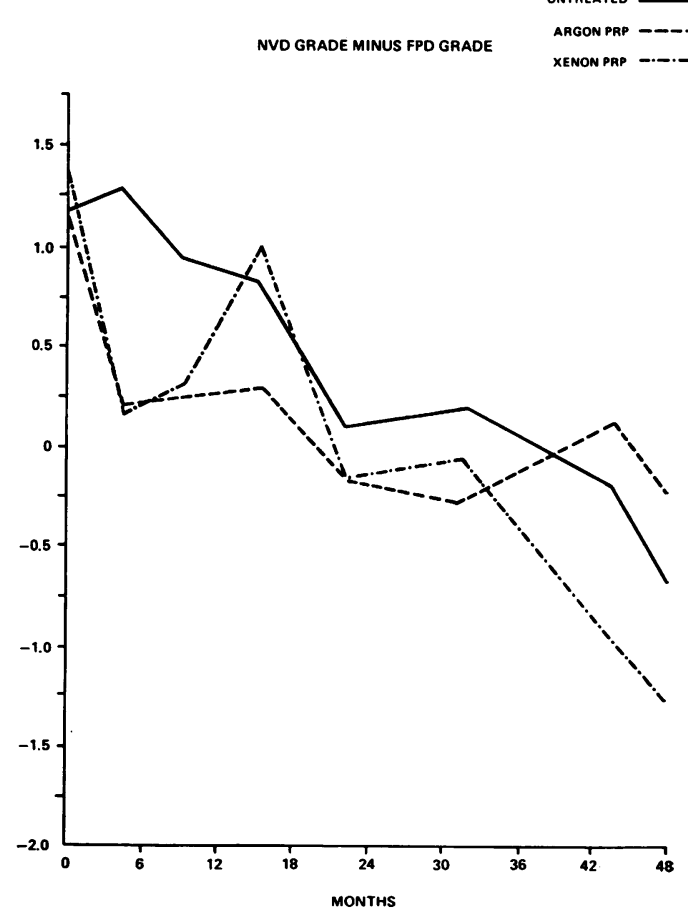

Fig. 9 NVD grade minus FPD grade. 

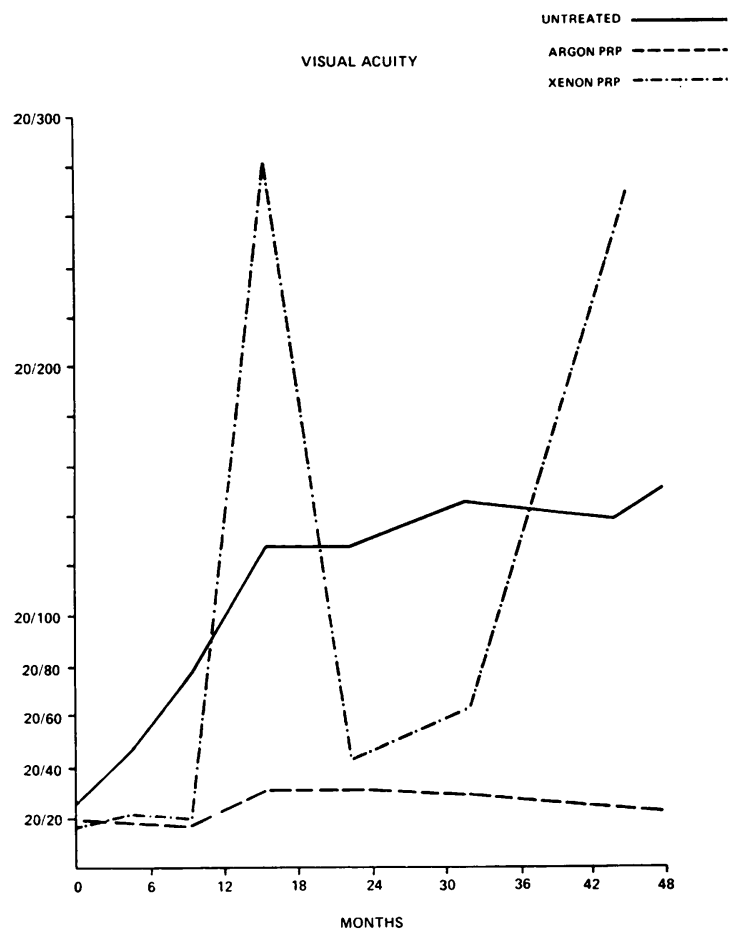

Fig. 10 Visual acuity of treated and untreated eyes.

of disc new proliferation either by preventing it from occurring or by shortening the duration of the disc pathology, hence reducing its adverse effect sequela.

A few observations and conclusions can be drawn from the results of the study:

Treated eyes, either argon- or xenon-treated, had less NVD at the end of the 4 years of follow-up than they had before they were treated. Untreated eyes had more NVD at the end of the follow-up period than they had at the beginning of the study.

Treated eyes, either with argon or with xenon, had less NVD and FPD at the end of the 4-year follow-up than had untreated eyes. The decrease in NVD grade in the present study in the treated eyes is 2.5 times that in the untreated eyes, and the increase in NVD grade in the untreated eyes is 3 times the increase in the treated eyes. This corresponds with the British Multicentric Photocoagulation Trial ${ }^{27}$ and with the Diabetic Retinopathy Study Group's observations, ${ }^{28}{ }^{29}$ which showed that treatment of eyes with NVD either with xenon or with argon was beneficial to all kinds of NVD, with or without vitreous haemorrhage, and that the rate of disappearance of NVD in the treated eyes was 4 times that in untreated eyes, and that NVD existed 2-fold in untreated eyes compared to treated eyes.
The involution of active neovascularisation and reduction of vitreous haemorrhage noted in the previously listed studies ${ }^{27-29}$ and in our study in both argon laser and xenon photocoagulated eyes was most encouraging. However, we felt that a closer analysis of fibrous proliferation from the disc in these treated eyes had a major clinical significance. A common observation after involution of neovascularisation is the development of traction retinal detachment in the posterior pole, which may extend to the macula. NVD disappears on 2 lanes: it is either replaced by FPD or merely regresses without being replaced by FPD. The longer NVD exists, as in the untreated eyes, the more likely it is that it will disappear along the first lane, that is, by being replaced by FPD. The shorter time it exists and the lesser grade it is, the less fibrous proliferation will occur on the disc when it regresses. This was shown by the fact that FPD grade in untreated eyes increased considerably while FPD grade in treated eyes increased slightly or moderately. Our observation of much less fibrous proliferation after photocoagulation of early NVD suggests an additional benefit to the diabetic patient of prompt recognition and treatment of NVD. The signicantly greater extent of FPD in xenon-treated eyes than argon laser-treated eyes which we have demonstrated (Table 13) represents an important detrimental effect of this modality, if longer follow-up shows a higher incidence of traction retinal detachment in this group. Further studies of FPD and its long-term consequences may help elucidate this issue.

There is no significant difference in the effect on disc NVD between argon- and xenon-treated eyes.

Correspondingly, treated eyes which show following treatment less NVD and FPD have better visual acuity than untreated eyes. As already pointed out ${ }^{31}$ visual acuity measurements do not reflect the NVD and FPD status at each follow-up period. There is a tendency for untreated eyes to have over the long run a worse visual acuity; but it often happens during various follow-up visits that eyes with very advanced NVD still have good vision, while eyes with less advanced NVD have less good vision, due to vitreous haemorrhage or macular oedema. In this study these accidental variations are reflected by the xenon-treated eyes curve (Fig. 10), because these eyes had more vitreous haemorrhage from NVD and NVE than argon-treated eyes during the follow-up period.

If NVD exists, earlier treatment will probably induce regression of blood vessels better than later treatment or no treatment at all, and may also reduce future development of FPD. This conclusion is confirmed by the findings of the Diabetic Retino- 
pathy Study Group ${ }^{28}{ }^{29}$ and Hercules et al., ${ }^{30}$ who a dvocate early treatment.

\section{References}

${ }^{1}$ Taylor E, Dobree JH. Proliferative diabetic retinopathy: site and size of initial lesions. Br J Ophthalmol 1970; 54:11. ${ }^{2}$ Little HL. Argon laser photocoagulation of proliferative diabetic retinopathy. Int Ophthalmol Clin 1976; 16:79-103.

${ }^{3}$ Toussaint D, Kuwabara T, Cogan DG. Retinal vascular pattern. II. Human retinal vessels studied in three dimensions. Arch. Ophthalmol 1961; 65:575.

${ }^{4}$ Wise GN. Retinal neovascularization. Trans Am Ophthalmol Soc 1956; 54:729.

${ }^{5}$ Deckert T, Simonsen SVE, Paulson JE. Prognosis of proliferative retinopathy in juvenile diabetics. Diabetes 1967; 16:728.

${ }^{6}$ Beetham WP, Aiello LM, Balomides MC, Koncz L. Ruby laser photocoagulation of early diabetic neovascular retinopathy. Arch Ophthalmol 1970; 83:261-272.

${ }^{7}$ Patz A, Berkow J. Visual prognosis in advanced diabetic retinopathy. In: Goldberg M, Fine S, eds. Symposium on Treatment of Diabetic Retinopathy, U.S. Department o Health, Education, and Welfare, Publication No. 1890, $1968 ; 87-91$.

${ }^{8}$ Patz A, Berkow JW. Visual and systemic prognosis in diabetic retinopathy. Trans Am Acad Ophthalmol Otolaryngol 1968; 72: 253-257.

${ }^{8}$ Patz A. Photocoagulation of diabetic disc neovascularization. In: Lynn JR, Snyder WB, Vaiser A, eds. Diabetic Retinopathy. New York: Grune and Stratton, 1974; 241249.

${ }^{10}$ Davis MD. Definition, classification, and course of diabetic retinopathy. In: Lynn JR, Snyder WB, Vaiser A, eds. Diabetic Retinopathy. New York: Grune and Stratton, 1974; 7-33.

"Davis MD. Natural course of diabetic retinopathy. In: Kimura, Caygill eds. Vascular Complications of Diabete Mellitus. St. Louis: Mosby, 1967; 139.

${ }^{12}$ Aiello LM, Beetham W, Baladimos MC, Chazan BI, Bradely RF. Ruby laser photocoagulation in treatment of proliferative diabetic retinopathy. Report. In: Goldberg M, Fine S, eds. Symposium on Treatment of Diabetic Retinopathy. US Department of Health, Education, and Welfare, Publication No. 1890, 1968; 434-465.

${ }^{13}$ Aiello LM, Briones JC. Ruby laser photocoagulation of proliferative diabetic retinopathy: Five-year follow-up. Int Ophthalmol Clin 1976; 16:4.

${ }^{14}$ Wessing A, Meyer-Schwickerath G. Results of photocoagulation in diabetic retinopathy. In: Goldberg MF, Fine SL, eds. Symposium on Treatment of Diabetic Retinopathy. US Department of Health, Education, and Welfare, Publication No. 1890, 1968: 569-592.

${ }^{15}$ Krill AE, Archer FRCS, Newell FW, Chishti MI. Photocoagulation in diabetic retinopathy. $A m J$ Ophthalmol 1971; 72: 299-321.
${ }^{16}$ Okun E. The effectiveness of photocoagulation in the therapy of proliferative diabetic retinopathy (PDR): A controlled study in 50 patients. Trans Am Acad Ophthalmol Otolaryngol 1968; 72:253-258.

${ }^{17}$ Okun E. Selection of cases for photocoagulation by xenon or argon. In: Lynn JR, Snyder WB, Vaiser A, eds. Diabetic Retinopathy. New York: Grune and Stratton, 1974; 127-1 32.

${ }^{18}$ James WA, L'Esperance FH. Treatment of diabetic optic nerve neovascularization by extensive retinal photocoagulation. Am J Ophthalmol 1974; 78:939-947.

${ }^{19}$ Zweng HC, Little HL, Peabody RR. Further observations on argon laser photocoagulation of diabetic retinopathy. Trans Am Acad Ophthalmol Otolaryngol 1972; 76:990.

${ }^{20} \mathrm{Z}$ weng HC. Selection of cases of diabetic retinopathy for treatment by argon laser slit lamp photocoagulation. In: Lynn JR, Snyder WB, Vaiser A, eds. Diabetic Retinopathy. New York: Grune and Stratton 1974; 109-125.

${ }^{21}$ Little HL. Retinal neovascularization in diabetes mellitus and the role of fluorescein angiography in argon laser photocoagulation. In: Lynn JR, Snyder WB, Vaiser A, eds. Diabetic Retinopathy. New York: Grune and Stratton, 1974; 133-144.

${ }^{22}$ Little HL, Zweng HC, Jack RL, Vassiliadis A. Techniques of argon laser photocoagulation of diabetic disc new vessels. Am J Ophthalmol 1976; 82:675-683.

${ }^{23}$ Zweng HC, Little HL, Vassiliadis A. Argon Laser Photocoagulation. St Louis: C. V. Mosby, 1977; 180-217.

${ }^{24} \mathrm{~L}$ 'Esperance FH. Argon laser photocoagulation in diabetic lesions. In: Lynn JR, Snyder WB, Vaiser A, eds. Diabetic Retinopathy. New York: Grune and Stratton, 1974; 145169.

${ }^{25}$ L'Esperance FH. Focal photocoagulation of retinovitreal neovascularization. Int Ophthalmol Clin 1976; 16:79-103.

${ }^{26}$ Arribas NP, Johnston GP, Okun E. Photocoagulation in diabetic retinopathy. Int Ophthalmol Clin 1976; 16:59-77.

${ }^{27}$ British Multicentric Photocoagulation Trial (1977). Proliferative diabetic retinopathy: treatment with xenon arc photocoagulation. Br Med J 1977; 1:739-741.

${ }^{28}$ Diabetic Retinopathy Study Research Group. Preliminary report on effects of photocoagulation therapy. Am J Ophthalmol 1976; $81: 383$.

${ }^{29}$ Diabetic Retinopathy Study Research Group. Photocoagulation treatment of proliferative diabetic retinopathy. Trans Am Acad Ophthalmol Otol 1978; 85:82-106.

${ }^{30}$ Hercules BL, Gayed II, Lucas SB, Jeacock J. Peripheral retinal ablation in the treatment of proliferative diabetic retinopathy: a three-year interim report of a randomised, controlled study using the argon laser. $\mathrm{Br} J$ Ophthalmol $1977 ; 61: 555-563$.

${ }^{31}$ Yassur Y, Pickle LW, Fine SL, Singerman L, Orth DH, Patz A. Optic disc neovascularisation in diabetic retinopathy: I. A system for grading proliferation at the optic nerve head in patients with proliferative diabetic retinopathy. Br J Ophthalmol 1980; 64:69-76.

${ }^{32}$ Diabetic Retinopathy Study. Manual of Operations. Baltimore: Diabetic Retinopathy Coordinating Center, 1972. 